\title{
A ontologia do negativo: na lingua, verdadeiramente, só existem diferenças?
}

Patrice Maniglier ${ }^{2}$

\section{É DE MUITO BOM TOM SEPARAR O ESTRUTURALISMO COMO MÉTODO PARA AS CIÊNCIAS HUMANAS E O} ESTRUTURALISMO COMO EVENTO MEDIÁTICO que, nessa consciência que uma época toma de si através dos jornais, teria vindo substituir o existencialismo, antes de ceder o passo diante das "filosofias da diferença”. A infelicidade é que uma leitura pouco atenta das próprias análises estruturais faz aparecer uma diversidade muito grande de métodos. Também é possível se propor a considerar o estruturalismo não como um método nem como uma doutrina, mas como um campo problemático, e a buscar sua unidade precisamente na maneira com a qual diversas atividades teóricas se encontraram - cada vez por razões singulares e, em alguns aspectos, heterogêneas - confrontadas com problemas filosóficos análogos. Esse encontro entre projetos positivos e especulações filosóficas, essa espécie de excesso especulativo que se impõe e se reimpõe no seio mesmo das abordagens teóricas, permitiria apreender o estruturalismo como movimento ou como acontecimento. Assim se compreenderia como essa intensa atividade filosófica encarnada pelos nomes de Althusser, Foucault, Deleuze ou Derrida tenha podido se escorar em trabalhos modestos de fonologia diacrônica (a recíproca sendo mais rara).

Os textos de Saussure, do qual se começa somente a ter uma ideia um pouco mais completa, para além da apresentação que Bally e Séchehaye fizeram deles, encontram-se num estado particularmente favorável a uma leitura desse gênero. De fato, Saussure parte de um problema que se poderia dizer metodológico: os fenômenos da linguagem se apresentam ao mesmo tempo como heterogêneos (alguns são fônicos; outros, articulatórios; outros, semânticos etc.), contínuos (não existe nenhum critério experimental para delimitar as unidades da linguagem, por exemplo, a partir da observação das curvas de frequências ou da fisiologia do aparelho fonador) e dessemelhantes (diferentes atualizações de uma mesma palavra, por exemplo, "senhores”, não preservam nenhum perfil acústico, fisiológico ou semântico). A tese semiológica vem responder a esse problema metodológico: a identificação e a delimitação das unidades linguísticas se fazem por associação entre uma ou muitas diferenças sonoras e uma ou muitas diferenças psicológicas. Mas essas unidades então apresentam propriedades estranhas: elas são duplas, nem totalmente físicas, nem totalmente psicológicas, e constituídas unicamente de diferenças. Portanto, ao fazer isso, Saussure introduz uma hipótese ontológica

\footnotetext{
${ }^{1}$ Tradução de Fábio Roberto Lucas, que desenvolve seu pós-doutorado em Estudos Literários na Universidade Federal do Paraná com apoio da Bolsa PNPD/Capes. Texto cedido pelo autor especialmente para ser traduzido para o português do original em francês. Ver MANiglier, Patrice. Methodos, n. 7, 2007. Disponível em: https://doi.org/10.4000/methodos.674. Acesso em: 27 jul. 2020. Trechos citados de outros livros ou artigos escritos em língua francesa e sem tradução em português também são apresentados em tradução livre. Nos outros casos, atualizamos a referência bibliográfica para indicar fontes já traduzidas e publicadas em língua portuguesa.

${ }^{2}$ Professor de Filosofia da Universidade Paris Nanterre. Contato: patrice.maniglier@gmail.com.
} 
forte, que não cessará de mobilizar sua recepção, especialmente através das grandes construções filosóficas de Gilles Deleuze ${ }^{3}$ e Derrida ${ }^{4}$.

Essa tese segundo a qual "na língua, só existem diferenças" está seguramente no coração do estruturalismo como movimento no sentido em que o definimos. Melhor, pode-se compreender a partir dela a estranha inversão aparente constituída por aquilo que alguns diagnosticaram como a passagem das filosofias da estrutura às filosofias da diferença. Mas ela tem também interesse por estar no coração de certas críticas feitas ao estruturalismo, entendido como interpretação filosófica de enunciados teóricos. Assim, Vincent Descombes dizia simplesmente:

Foram retidos da análise estrutural certos slogans (que os filósofos se apressaram em entender num sentido dialético ou neodialético): só existem diferenças, não termos que diferem. Esses slogans foram justamente criticados como sendo obscuros ou ridículos: se existe uma diferença, é preciso que existam coisas que difiram sob certa relação ${ }^{5}$.

É verdade ser impossível fingir que uma tese filosófica paradoxal se tornaria suficientemente explícita pelo mero fato de um linguista apresentá-la como necessária para a construção de sua própria teoria. De resto, JeanClaude Milner procurou mostrar que uma teoria experimental da linguagem podia muito bem dispensar esse problema, e é precisamente o que fez Chomsky ${ }^{6}$. Tentaremos, todavia, sugerir qual custo propriamente teórico supõe essa evasão do problema filosófico e quais argumentos empíricos poderiam ser invocados em favor da posição saussureana. Mas tentaremos, sobretudo, mostrar que a ontologia negativa aparentemente admitida por Saussure é apenas aparente, e que a teoria do valor esconde, em realidade, uma construção nitidamente mais complexa na qual, com efeito, projeto teórico e questões filosóficas se interpelam e se relançam.

\section{Os paradoxos de uma ontologia do negativo}

Para compreender bem o problema de Saussure, é preciso inicialmente compreender as razões teóricas que o motivam. Pois se é verdade que não se pode fundar apenas sobre a afirmação de Saussure toda uma nova ontologia, não é verdade, todavia, que o linguista possa simplesmente dispensar a hipótese ontológica e aplicar tranquilamente o método estrutural. Ou mais exatamente, ele pode fazê-lo, mas a certo custo teórico. Autores como Troubetzkoy, Jakobson ou Martinet, por exemplo, podem muito bem não se colocar a questão ontológica, mas na medida em que eles definem a linguagem como um meio de comunicação ${ }^{7}$. Ora, isso implica, ao menos, que

\footnotetext{
${ }^{3}$ DELEUZE, Gilles. Différence et Répétition. Paris: PUF, 1968. DeleuZE, Gilles. Logique du sens. Paris: Minuit, 1969.

${ }^{4}$ Derrida, Jacques. De la Grammatologie. Paris: Minuit, 1967. DerridA, Jacques. Marges de la Philosophie. Paris: Minuit, 1972.

${ }^{5}$ DESCOMBES, Vincent. Le même et l'autre, Quarante-cinq ans de philosophie française (1933-1978). Paris: Minuit, 1979 , p. 182.

${ }^{6}$ MiLnER, Jean-Claude. O amor da Língua. Campinas: Editora Unicamp, 2012, p. 62-63.

7 "O funcionamento do fonema na língua é um fenômeno que nos leva à conclusão: o fonema funciona, ergo ele existe. Muito se discutiu sobre o modo dessa existência: essa questão, concernindo não somente o fonema, mas todo valor linguístico em geral, está evidentemente fora do alcance da fonologia e mesmo de toda a linguística, e seria mais sensato abandoná-la à filosofia, particularmente à ontologia, que especula sobre o ser. A tarefa que se impõe ao linguista é a análise aprofundada do fonema, o estudo sistemático de sua estrutura”. JAKOBSON, Roman e WAUGH, Linda. La charpente
} 
aquilo que há a comunicar esteja determinado em si. Do mesmo modo, seria possível muito bem dizer, por exemplo, que as nuances qualitativas são índices permitindo reconhecer um signo que pode ser, sim, definido positivamente, em relação a um "pensamento" ou uma "representação". Nesse caso, os traços distintivos funcionariam simplesmente como critérios que permitem identificar uma entidade perfeitamente definida nela mesma, talvez até mesmo uma "representação fonológica" para retomar o vocabulário dos Prinćípios de fonologia generativa de Chomsky ${ }^{8}$. Essa entidade não tem seguramente nada de "diferencial" em si, nem de opositivo, e não traz nenhum problema ontológico novo: ela se contenta em recolocar a questão do "mental" em termos bastante tradicionais. Pode-se dizer que uma "unidade linguística" é identificada com a ajuda de certos traços diferenciais. Por exemplo, eu "reconheço p", não porque possuo uma espécie de retrato falado ou automático da impressão $p$, mas porque estou atento aos traços distintivos particulares no fenômeno fônico que me permitem inferir $p$. Mas isso não significa que $p$ seja com isso puramente diferencial: trata-se de um símbolo definido por sua função em um cálculo, graças a qual se obtém fórmulas cuja interpretação é heterogênea ao sistema simbólico em si. Assim, não há nenhuma consequência direta entre a tese do caráter distintivo do nível fonológico (que persiste ainda em nossos dias como a base instrumental de toda fonologia) e a tese ontológica forte que Saussure crê encontrar nela. Se os fonemas são "diferenciais", isso significa simplesmente que o sujeito falante busca, nas realizações sonoras da linguagem, algo com o qual distinguir "representações" que ele é suscetível de ter. É porque esse nível é somente um meio que ele é, precisamente, distintivo.

Além disso, é sobre essa ideia que Thomas Pavel apoia sua crítica às tentativas de recuperação filosófica da tese de "distintividade" dos signos e, em particular, às proposições de J. Derrida em "A diferença"”.

A exemplo dos signos saussureanos, os vestígios [traços / traces] constituem um sistema aberto onde cada posição não é definida senão por sua não identidade com as posições que a cercam. Mas a razão pela qual os sistemas de signos adotam essa estrutura vem da economia de meios e não da negatividade transcendental. Os linguistas identificaram sistemas diferenciais precisamente lá onde a língua, dispondo de meios limitados, deve chegar a um rendimento máximo $^{10}$.

Em outras palavras, essa propriedade seria perfeitamente banal (o que, de resto, Martinet sempre disse). Certo, mas isso implica uma posição sobre a semântica, posição legítima, seguramente, porém difícil de sustentar, pois ela exclui totalmente a distintividade do domínio do sentido. Não é, de modo nenhum, seguro que tal exclusão (na semântica cognitiva, por exemplo) tenha tido resultados convincentes, e os trabalhos de François

\footnotetext{
phonique du langage. Paris: Minuit, 1980, p. 79. Mas essa maneira de afastar o problema ontológico finalmente só é possível porque o fonema é definido por sua função na língua. Troubetzkoy, ao expor o debate sobre o estatuto do fonema, recorre à mesma solução, ou melhor, à mesma maneira de evitar o problema. O que os obriga a pressupor a função da linguagem (comunicar) em vez de fazer dessa própria função um objeto de pesquisa positiva. TROUBETZKOY, N. S. Principes de phonologie. Paris: Librairie C. Klincksieck, 1949, p. 44.

${ }^{8}$ Chomsky, Noam e Halle, Morris. Principes de phonologie générative, Paris: Minuit, 1973, p. 35-38; 59-63.

${ }^{9}$ DERridA, Jacques. Margens da filosofia. Campinas: Papirus, 1991, p. 33-64.

${ }^{10}$ PAVEL, Thomas. A miragem linguística, ensaio sobre a modernidade in telectual. Campinas: Pontes, 1990 , p. 106.
} 
Rastier testemunham que uma nova semântica estrutural pode plenamente reivindicar sua pertinência ${ }^{11}$. Em todo caso, é certo que Saussure desejava estender à face semântica da linguagem (o "conceito") a tese diferencialista que se impunha com toda evidência para sua face fônica (a "impressão acústica"): "Não há ideias positivas dadas"12, ele dizia. "Assim, sol parece representar uma ideia perfeitamente positiva, precisa e determinada, assim como a palavra lua: entretanto, quando Diógenes diz a Alexandre 'Sai da frente do meu sol!', não há mais, em sol, nada de sol a não ser a oposição com a ideia de sombra (...)"13. Vê-se que Saussure escolheu um exemplo aparentemente desfavorável para sua tese, um no qual o signo parece designar uma coisa que aparenta ser perfeitamente determinada, pois única, para mostrar que, em todos os casos, a significação é negativa. Na verdade, nesse caso, "sol" não designa o astro ele mesmo, mas, sim, a luz que dele provém, e se opõe, portanto, à sombra, mais que à lua. Ademais, essa é a razão pela qual não há diferença entre o uso referencial e o uso metafórico do termo ${ }^{14}$ : a designação do astro não vem "primeiro" em relação à da luz. A pluralidade dos usos de um termo decorre precisamente dessa indeterminação intrínseca. É também a verdadeira razão que Saussure dá para recusar a representação da língua como nomenclatura. O que é "conteúdo" semanticamente em uma entidade dada de língua não é outra coisa que a combinação de certos traços determinados.

Vê-se que o problema saussureano só se coloca com a condição de que se aplique ao "significado" o que parece valer antes de tudo para o "significante". Isso significa que os traços diferenciais não permitem identificar qualquer coisa, pois o que se trata de identificar ou de reconhecer na ocasião de um ato de fala particular é precisamente um conjunto de diferenças, e unicamente isso. Não há diferença entre os critérios de identificação de uma coisa e a coisa ela mesma: "Para o fato linguístico, elemento e característica são eternamente a mesma coisa. É próprio da língua, como de todo sistema semiológico, não admitir nenhuma diferença entre o que distingue uma coisa e o que a constitui (porque as "coisas" de que se fala aqui são signos, que não têm outra missão, essência, além do fato de ser distintos)"15. Os traços diferenciais não são somente marcas, mas são constitutivos do próprio objeto, como se as marcas não tivessem, no fim das contas, nada a marcar... Esse paradoxo é próprio a Saussure, e sem dúvida somente a ele na tradição linguística. Não é preciso polir seu gume, pois, pelo contrário, é ele que Saussure quer deixar saliente. Inversamente, é preciso mostrar o que, à primeira vista, a tese saussureana tem de inaceitável.

Normalmente, a diferença vem funcionar como critério do reconhecimento de uma identidade. Com isso, pode-se definir um som por seus intervalos. Mas o que então se limita é um "corte de sonoridade", por exemplo, uma banda de frequência. Seria um mal jogo de palavras dizer que essa porção de espaço é "constituída" por seus

\footnotetext{
${ }^{11}$ RASTIER, François. Sémantique interprétative. Paris: PUF, 1987. RASTIER, François. Sémantique et recherches cognitives. Paris: PUF, 1991.

${ }^{12}$ SAussure, Ferdinand de. Cours de linguistique générale, éd. Rudolf Engler, Wiesbaden: Otto Harrassowitz, Tome 1, 1967, P. 71, n. 1941. Os textos das aulas de Saussure serão sistematicamente citados a partir da edição crítica do Cours de linguistique générale, estabelecida por Rudolf Engler (Ibid.), às vezes com a menção da passagem do Curso de Linguística Geral na edição brasileira (Curso de Linguística Geral. São Paulo: Cultrix, 2006, abreviado CLG). Trata-se, portanto, do texto dos cadernos dos estudantes. Para a edição Engler, a partir daqui, será fornecido o número da página e do fragmento.

${ }^{13}$ SAUSSURE, Ferdinand de. Escritos de linguística geral. São Paulo: Cultrix, 2004, p. 68. Abreviado ELG daqui em diante.

${ }^{14}$ Cf. o exemplo da flor: "uma palavra pode exprimir ideias bastante diferentes sem que sua identidade fique seriamente comprometida (cf. 'adotar uma moda' e 'adotar uma criança', 'a flor da macieira' e ‘a flor da nobreza' etc.)”. CLG, p. 126.

${ }^{15}$ SAUSSURE, Ferdinand de. Escritos de linguística geral, op. cit., p. 224. Fórmula idêntica nos “aforismos”. Ibid., p. 109.
} 
próprios limites. Os limites são os limites de alguma coisa: entre tal e tal limite, tudo o que surge será considerado como uma só e mesma coisa. É possível que a definição de uma coisa implique necessariamente a delimitação, em outras palavras, que ela só possa se fazer por uma marcação das fronteiras ou, como se diz, por demarcação. Mas isso não significa que a coisa seja intrinsecamente negativa. Assim, se o animal de $O$ Covil, de Kafka, pergunta-se onde começa e onde termina seu território, é, sim, "alguma coisa" que ele se propõe identificar, neste caso, "seu território": o conteúdo dessa alguma coisa é positivo, trata-se de certos direitos que ele acredita ter ou que lhe são atribuídos, em suma, um conceito. Os limites vêm, portanto, definir a extensão de um conceito que ele e outros, em tese, têm em comum, o de "meu território". A infelicidade do animal de Kafka é precisamente ele estar sozinho ao se colocar essa questão, que assim se torna interminável e ainda mais dolorosa que uma resposta desagradável... Em outros termos, não é porque a diferença é o único meio para reconhecer uma coisa que essa coisa é negativa. Pode-se perguntar se Saussure não caiu em uma confusão desse gênero.

Mais grave, não se vê como se pode passar dessa tese sobre o caráter diferencial dos signos à noção de unidade, ou seja, à descontinuidade que é precisamente aquilo de que Saussure procura dar conta. Com efeito, se um signo realizado é o conjunto dos traços qualitativos distintivos que permitem separá-lo de outro, ou seja, se o signo "sol" não é senão a diferença acústica que se faz de ouvi-la, não se vê no que isso teria como constituir, de qualquer maneira que fosse, uma unidade. Há, sim, nuances, mas nenhuma saberia dar lugar a uma unidade distintiva. Se a diferença não é diferença de nada, ou entre nada e nada, mas "diferença pura", não se vê por que ela deveria ter um valor distintivo. Assim, para Bergson, é precisamente à medida que a diferença não é distintiva, mas, pelo contrário, contínua, que se pode dizer que há "diferenças em si”: trata-se de uma pura variação qualitativa não marcada, que não tem nem começo nem fim, e que não teria como separar duas coisas.

De fato, o problema - uma vez que se supõe que a língua atue sobre um só plano qualitativo - é que se torna impossível compreender como as diferenças podem constituir uma unidade que não seria, ela própria, separável de suas próprias marcas. Com isso, fica-se perdido em paradoxos inextricáveis que podem servir de metafísica sutil desde que não se olhe muito para eles. Mas caso seja reintroduzida a dualidade, a coisa se ilumina. Os editores exprimiram isso muito bem: "Mas dizer que na língua tudo é negativo só é verdade em relação ao significante e ao significado tomados separadamente: desde que consideremos o signo em sua totalidade, achamo-nos perante uma coisa positiva em sua ordem" ${ }^{16}$. Saussure havia começado a explicar esse ponto justamente na última aula de linguística geral que ele teria proferido.

[1944] Só há diferenças caso se fale seja dos significados, seja dos significantes. Quando se chega aos próprios termos, resultados da relação entre significante e significado, pode-se falar de oposições [...]

[1941] 'Só existem diferenças; e nenhum mínimo termo positivo', aqui, é de uma diferença do significante que falamos. $\mathrm{O}$ jogo dos significantes está fundado sobre diferenças. O mesmo para os significados: só existem diferenças que serão condicionadas pelas diferenças de ordem acústica [...]

[1945] Graças ao fato de as diferenças se condicionarem umas às outras, teremos alguma coisa que pode se assemelhar a termos positivos pela tomada em consideração de tal diferença da

\footnotetext{
${ }^{16}$ CLG, p. 139.
} 
ideia com tal diferença do signo. Pode-se então falar da oposição dos termos e, portanto, não manter que só existem diferenças 'por causa desse elemento positivo da combinação, ${ }^{17}$.

Esse texto é essencial porque ele mostra duas coisas. Inicialmente, que as realidades mentais que constituem a linguagem não são "entidades puramente negativas", mesmo se elas não correspondem a nenhuma classe de acontecimentos substanciais dados. Elas são entidades perfeitamente positivas, e é ademais precisamente porque elas o são que elas são reais. Quero dizer que a "realidade" mental, que deixa sua marca no cérebro e constitui um elemento do "tesouro mental" que é a língua ${ }^{18}$, é essa positividade mesma. Todavia, essa positividade é um resultado, um resíduo, um resto, uma consequência involuntária, uma positividade induzida que não corresponde a nada de dado. É que não se pode contentar em definir a positividade do signo como uma correlação de diferenças: trata-se de uma correlação entre diferenças oposta a outras correlações. Esse texto mostra também que Saussure efetivamente entende a negatividade sempre em dois sentidos, por um lado, como diferença, e, por outro, como oposição ${ }^{19}$. Veremos que essa distinção está no coração da teoria do valor, uma teoria que propõe uma verdadeira gênese das positividades semiológicas sem, contudo, corresponder nem a uma gênese empirista (abstração das identidades a partir da repetição dos dados qualitativos) nem a uma gênese racionalista (projeção sobre o dado qualitativo de uma forma dada no espírito).

\section{Gênese do valor}

Para compreender como, da simples correlação entre diferenças, podem nascer termos positivos, é preciso partir de uma situação na qual os termos não estão dados. Talvez se esteja tentado a crer que isso significa que somente as diferenças estão dadas: não teríamos ainda as coisas quentes e as coisas frias, mas desde já o contraste do quente e do frio. Esses contrastes seriam retidos como "traços distintivos" e nós os associaríamos uns aos outros para definir uma entidade negativa, à maneira de Jakobson para o fonema ${ }^{20}$. Mas, em realidade, não há nenhuma razão para crer que as variações qualitativas se dão prontamente sob a forma do contraste. Entre um som mais estridente e um som mais abafado, não há hierarquia qualitativa, mas somente uma alteridade. O aspecto gradual da experiência não está na própria experiência. Todo o sentido da crítica da noção de

\footnotetext{
${ }^{17}$ SAUSSURE, Ferdinand de. Cours de linguistique générale, op. cit., p. 272, n. 1944sq.

${ }^{18}$ Esse aspecto particularmente incômodo do pensamento de Saussure geralmente não é revelado. Porém, ele está no coração do problema que o linguista busca levantar. Para alguns elementos no mesmo sentido, ver sobretudo MANIGLIER, Patrice. La langue, cosa mentale. In: Saussure. Paris: Editions de l' Herne, 2003.

19 Troubetzkoy não admitia a distinção conceitual entre diferença e oposição: "A ideia de diferença supõe a ideia de oposição”. TroubetZkoy, N. S. Principes de phonologie, op. cit., p. 33. Essa posição nos parece totalmente coerente com um postulado funcionalista, que será mais bem explicitado por Jakobson. Deleuze, renovadamente, viu muito bem a importância conceitual dessa recusa de distinguir diferença e oposição (ainda que ele a atribua a Saussure) bem como sua ligação com uma abordagem funcionalista da linguagem, ou seja, que postula o sentido como alguma coisa já dada, indiferente para o linguista cujo objeto seria unicamente as "ferramentas", como dirá Chomsky, de reconhecimento da significação: "Quando interpretamos as diferenças como negativas e com a categoria da oposição, já não estaríamos do lado daquele que escuta e até mesmo que ouviu mal, que hesita entre várias versões atuais possíveis, que tenta 'reconhecer-se' pelo estabelecimento de oposições, o pequeno lado da linguagem, não o lado daquele que fala e que atribui sentido?". DELEUZE, Gilles. Diferença e Repetição. São Paulo: Graal, 2009, p. 289.

${ }^{20}$ JAKOBSON, Roman. Essais de linguistique générale. Paris: Minuit, 1963, p. 103-107.
} 
intensidade feita por Bergson, no primeiro capítulo de Dados imediatos da consciência, está em mostrar que uma variação qualitativa não é em si ordenável e que não se tirará jamais, de uma simples variação qualitativa, uma "polaridade" 21 . Não obstante, Jakobson se esforçou precisamente em mostrar que os traços distintivos eram dados universais do espírito humano ${ }^{22}$.

Na verdade, não é filosoficamente impossível sustentar que a variação é em si uma diferença, mas apenas à condição de que a variação perca precisamente seu caráter qualitativo, ou mais exatamente, de que a dimensão qualitativa se torne uma modalidade "fenomenal" de uma realidade que não é, na verdade, nada qualitativa, mas, sim, espiritual e mesmo lógica. É bem isso que Hegel quis mostrar nas passagens justamente célebres da Ciência da Lógica consagradas à identidade, à diferença e à contradição ${ }^{23}$. Com efeito, a noção de uma diferença pura ou de uma diferença em si é contraditória em si, o que não quer dizer, para Hegel, que ela não é real, mas, pelo contrário, que ela testemunha ser o próprio real prontamente lógico, pois, de fato, a contradição é uma relação lógica. De modo que, se é possível mostrar que os constituintes elementares da experiência são eles próprios contraditórios (ou melhor, são modalidades da contradição, diria Hegel), isso significa que o dado sensível não é, inversamente ao que queria Kant, exterior ao espírito, mas, pelo contrário, uma das primeiras manifestações do Espírito, que é a própria contradição. O diverso sensível é, enquanto tal, uma ideia, mas uma ideia que não pode aparecer ela mesma senão como irredutível ao que é ideal. Pois, como se sabe, a diferença entre espiritual e não espiritual é interior ao próprio espírito e a sensação não é senão a primeira modalidade dessa contradição consigo mesma que é o espírito (também é com a sensação que começa a Fenomenologia do Espírito). A variação qualitativa, se ela tivesse de se dar prontamente como diferença, não teria, portanto, nada de estético, seria somente uma das primeiríssimas figuras da contradição interna e a melhor testemunha em favor do idealismo absoluto $^{24}$. Em outras palavras, o conceito de "diferença qualitativa" (que constituiria traços ou dimensões estruturantes a priori da experiência) é um conceito mal determinado, ao qual é melhor renunciar.

\footnotetext{
${ }^{21}$ É sabido que Bergson mostra que a noção de intensidade é um "misto" conceitual, mistura de qualidade pura e de movimento. A percepção de uma diferença de luz como uma diferença entre "mais" ou "menos" luminoso não provém da própria qualidade, mas de que essa qualidade, propõe Bergson, funcione como signo de um esforço a se fazer: seja para se aproximar a fim de ver melhor, seja, pelo contrário, para se afastar a fim de não ter a visão ofuscada etc. BERGSON, Henri. Ensaio sobre os dados imediatos da consciência. Lisboa: Edições 70, 1989, p. 23-39.

${ }^{22}$ cf. principalmente JAKOBSON e WAUGH, La charpente phonique du langage, op. cit., p. 212-216.

${ }^{23}$ Hegel, G. W. F. Ciência da Lógica: 2 - A Doutrina da Essência. Orsini. Petrópolis: Vozes, 2017, p. 53-92, primeira seção, capítulo segundo.

24 Vê-se aqui em que sentido a ambição "estruturalista" de ter construído outro conceito da "diferença em si” pôde justificadamente parecer, durante certo tempo, fornecer o elo perdido, se é possível dizê-lo, da operação de "materialização da dialética", que Marx e Engels haviam anunciado. Pode-se, com efeito, afirmar que a contradição é "material" caso se limite a entender esse conceito no sentido que é o seu, ou seja, o sentido lógico. Afunda-se então mais na mitologia do que na filosofia ou na "ciência". É bem isso que Althusser mostrou nitidamente. Porém, não é certo que Althusser tenha compreendido (ou admitido) que o materialismo dialético devia passar pela reconstrução de um conceito estético da diferença, o que teria podido levar a comparar o empreendimento de Marx ao de alguns pós-kantianos, em particular os de Salomon Maïmon e de Hoëne Wronski (cf. DELEUZE, Diferença e Repetição, op. cit., p. 248-250), mas também, mais tardiamente, de Hermann Cohen, que tentavam mostrar que não havia diferença entre a dialética e a estética, todavia não para, à maneira de Hegel, disparar o movimento de idealização do real, mas, pelo contrário, para "materializar" o espírito, ou melhor, afirmar a inutilidade de ultrapassar o momento da sensação. Caberá a Deleuze, particularmente em Diferença $e$ Repetição, ter claramente extraído essa solução. O problema de um materialismo dialético também é, entretanto, muito
} 
De fato, Saussure não diz de modo nenhum que as diferenças significantes e significadas são dadas, e que é ao associá-las que se fabrica a entidade linguística. Ele diz mesmo exatamente o contrário:

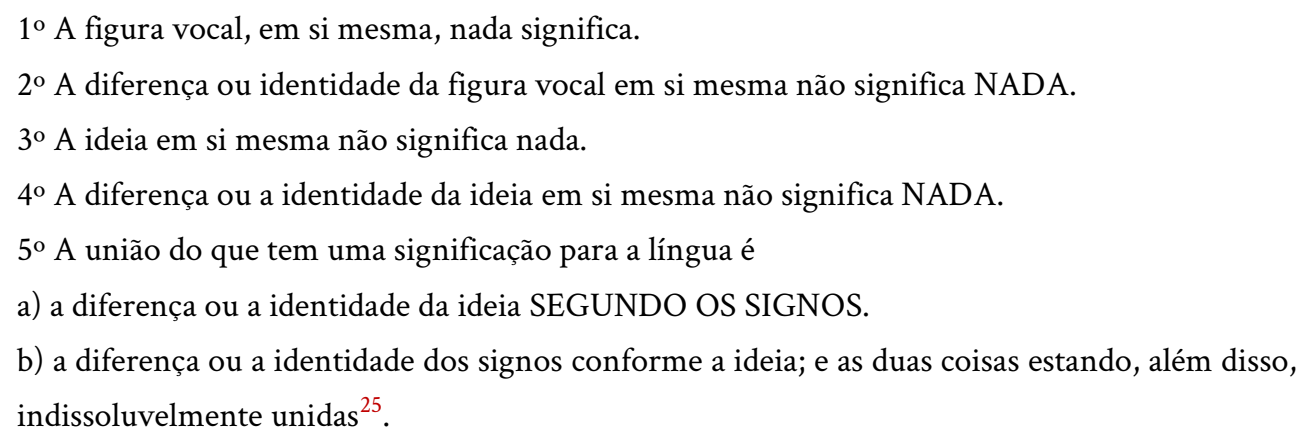

Em outras palavras, as diferenças não são dadas prontamente. Digamos que só são dadas as variações qualitativas, sem direção nem fim, igualmente incomparáveis. Mas uma variação qualitativa se torna uma diferença intensiva na medida em que ela é sistematicamente correlacionada com outra variação qualitativa que se encontra sobre outro plano qualitativo. Reservaremos o termo heterogêneo para designar a diferença entre os planos qualitativos. É somente à condição dessa correlação que se pode falar de uma diferença qualitativa: só há diferença qualitativa sobre um plano porque há outra diferença sobre um plano heterogêneo. Para haver uma diferença, é preciso sempre que haja duas. Só existe traço distintivo duplo: "Princípio fundamental da semiologia ou da 'língua' considerada regularmente como língua e não como resultado de estados precedentes. Não há, na língua, nem signos, nem significações, mas DIFERENÇAS de signos e DIFERENÇAS de significação; as quais $1^{\circ}$ só existem, absolutamente, umas através das outras (nos dois sentidos) sendo, portanto, inseparáveis e solidárias; mas $2^{\circ}$ não chegam jamais a se corresponder diretamente" ${ }^{26}$. A constituição de um plano semiológico supõe um trabalho de seleção de variações substanciais pela correlação delas com variações heterogêneas, e essa seleção as constitui, isolando-as, de fato, em traços diferenciais sobre seu próprio plano qualitativo. Assim, a qualidade de um "som da língua" não é determinada unicamente pelos sons que podem cercá-lo: somente certos contrastes sonoros são retidos, aqueles que são associados a contrastes "conceituais". Ou mais exatamente, somente certas variações são retidas, e aquelas que são retidas então funcionam como contrastes.

Todavia, com isso não foi explicado como emerge uma positividade do conjunto desses traços distintivos. Na verdade, é do mesmo movimento que nascem ao mesmo tempo traços distintivos e "singularidades" qualitativas. A correlação entre as variações instaura limiares no seio da experiência, que fazem bascular de um plano qualitativo a outro. Esses limiares não correspondem tanto a fronteiras "naturais" entre qualidades dadas sobre cada plano qualitativo, mas, sim, a pontos de basculamento sobre outro plano, arbitrariamente determinados pela associação ou correlação deles com variações heterogêneas, onde o jogo da diferenciação, se é possível dizêlo, recomeça com um conjunto de limiares todo outro. São essas fraturas que introduzem a descontinuidade na continuidade. São as variações sobre outro plano qualitativo que determinam as singularidades do primeiro.

presente em Lévi-Strauss (ver o artigo "Dialética” em MANIGLIER, Patrice. Le vocabulaire de Lévi-Strauss. Paris: Ellipses, 2002.

${ }^{25}$ ELG, p. 68.

${ }^{26}$ ELG, p. 65. 
Assim, se fosse preciso fazer uma comparação matemática, deveria ser dito que a língua é um conjunto de singularidades extraídas da relação entre duas funções, das quais uma é a derivada da outra, e reciprocamente ${ }^{27}$. Seria por uma espécie de reciprocação da derivação que seriam construídos, pedaço por pedaço, de modo dinâmico, as duas curvas, que não cessariam de se reatravessar uma a outra, um pouco à maneira de um ponto de basta [capiton], para retomar a metáfora muito acertada de Lacan ${ }^{28}$. A correlação entre os dois domínios de variações contínuas faz emergir essas descontinuidades que são os signos. É isso que Saussure queria dizer quando dizia que o pensamento-som implica divisões e comparava os valores às ondas. Os termos dessa primeira articulação não são senão esses pontos de basculamento de um registro de diferenciação qualitativa para outro: eles nascem "da combinação de tantos signos acústicos com tantos recortes no pensamento" ${ }^{29}$. São, portanto, experiências que efetivamente não correspondem a um conteúdo qualitativo particular, ou seja, não são substanciais, porque elas são apenas experiências das mudanças de substância dependendo de uma covariação.

Contudo, um traço distintivo não corresponde somente a um só outro traço distintivo heterogêneo, mas a um conjunto de traços distintivos heterogêneos. Assim, o traço da labialização que se reconhece em /sommeil/ (sono) não implica, sobre o plano do conteúdo, uma só variação, mas um conjunto de variações, aquelas que se deslocam de 'soleil' (sol) para 'sommeil'30 .'Soleil', por sua vez, caracteriza-se por um conjunto de traços sêmicos todo outro, que não se limitam à passagem da obscuridade à luz, mas se estendem à oposição do animado e do inanimado, por exemplo, da coisa e da atividade etc. Reciprocamente, bastaria fazer variar um só traço sêmico de 'soleil', por exemplo, a diferença do animado e do inanimado, para provocar um conjunto de variações sobre o plano de expressão, por exemplo, aquelas que se atualizam na imagem acústica /Jupiter/, que, com toda evidência, difere ela mesma de /soleil/ em um bom número de traços acústicos. Passa-se aqui dos "traços distintivos” selecionados às “unidades distintivas” que são nós de traços distintivos heterogêneos. São essas unidades que constituem o que Saussure chama de "formas". "FORMA = Não uma certa entidade positiva de uma ordem qualquer, e de uma ordem simples; mas a entidade ao mesmo tempo negativa e complexa: que resulta (sem nenhuma espécie de base material) da diferença com outras formas, COMBINADA à diferença de significação de outras formas" ${ }^{31}$.

É somente depois de se ter mostrado que singularidades emergiam apesar de nós da dupla determinação das diferenças qualitativas que se pode voltar à formulação paradoxal de Saussure: "um signo não é nada em si, ele é somente tudo aquilo que os outros não são”. Na verdade, deveria ser evidente que o fato de um termo poder ser determinado por oposição a termos circundantes supõe, como uma condição inevitável, que esses termos

\footnotetext{
${ }^{27}$ É possível apoiar essa interpretação em um texto de Saussure: com efeito, quando esse reprova os linguistas por separar as duas dimensões do signo, em um fragmento no qual ele compara o objeto linguístico a uma placa de ferro amarrada a um cavalo, ele os acusa de querer "partir pela tangente", acrescentando: "que me seja permitida uma expressão verdadeiramente muito justa aqui". ELG, p. 21-22. Como se, portanto, a "ideia” fosse a tangente da "forma”, e a "forma”, a tangente da "ideia”... ${ }^{28}$ LACAN, Jacques. O Seminário Livro 3, as psicoses, 1955-1956. Rio de Janeiro: Jorge Zahar, 1985, p. 303.

${ }^{29}$ SAUSSURE, Ferdinand de. Cours de linguistique générale, op. cit., p. 272, n. 1946.

${ }^{30}$ Utilizaremos as barras para indicar o valor fonológico (significante) e as aspas simples para indicar o valor semântico (significado). Colocaremos entre colchetes o valor total em si. Reservaremos, como se deve, as aspas duplas para a simples menção de um termo tal como ele pode aparecer em nosso próprio texto, em outras palavras, quando essa menção não corresponder a nenhuma definição técnica particular e não recair, portanto, em nenhuma separação "teórica" entre linguagem e metalinguagem.

${ }^{31}$ ELG, p. 36.
} 
circundantes sejam, por sua vez, dados, ou seja, preexistentes. Eles não poderiam ser dados pelo termo circundante que eles próprios determinam. Para sair dos falsos paradoxos da ideia de entidade "opositiva”, é preciso supor que o jogo da oposição se faz entre termos já dados, e que ele não poderia constituir os signos - mas que ele pode, por outro lado, redeterminá-los. Ora, um texto de Saussure testemunha sem ambiguidade que era assim que ele entendia a questão: nele, a determinação do valor é caracterizada pela oposição como uma forma de "pós-mediação reflexiva” ou de "pós-elaboração".

O fenômeno de integração ou de pós-meditação-reflexão é o fenômeno duplo que resume toda a vida ativa da linguagem e pelo qual

$1^{\circ}$ os signos existentes evocam MECANICAMENTE pelo simples fato de sua presença $a^{32}$ e do estado sempre acidental de suas DIFERENÇAS a cada momento da língua, um número igual não de conceitos, mas de valores opostos para nosso espírito (tanto gerais quanto particulares, uns chamados, por exemplo, de categorias gramaticais, outros tachados de fatos de sinonímia etc.); essa oposição de valores, que é um fato PURAMENTE NEGATIVO, se transforma em fato positivo, porque cada signo, ao evocar uma antítese com o conjunto de outros signos comparáveis em uma época qualquer, começando pelas categorias gerais e terminando pelas particulares, se vê delimitado, apesar de nós, em seu valor próprio [...].

A cada signo existente ${ }^{33}$ vem, então, SE INTEGRAR, se pós-elaborar, um valor determinado [], que só é determinado pelo conjunto de signos presentes ou ausentes no mesmo momento ${ }^{34}$.

Portanto, a posição de Saussure é clara: dizer que o signo é somente aquilo que os outros não são só é verdadeiro porque secundariamente o valor do signo vem se integrar ao signo. A definição do termo pela oposição, com isso, é sempre uma segunda determinação. A determinação do valor (da positividade de língua) é necessariamente uma determinação dupla ou uma dupla determinação: uma língua, ou mais geralmente todo sistema de valores, constitui-se sempre em duas etapas. Ela é dupla não no sentido em que o significante determina o significado que determina reciprocamente, por sua vez, o significante, também não no sentido em que os termos se determinariam uns aos outros reciprocamente, mas no sentido em que eles se constroem em dois momentos: a dualidade aqui não é mais recíproca, mas hierárquica. Ou seja, um valor é determinado ao mesmo tempo por um jogo diferencial e por um jogo opositivo.

Saussure separa diversas vezes a diferença e a oposição, e sempre da mesma maneira. Assim, ele compara a língua e a escrita para extrair quatro traços principais de todo valor: o primeiro é arbitrário, o segundo é o "valor puramente negativo ou diferencial do signo: ele retira seu valor exclusivamente das diferenças”. Esse traço é cuidadosamente distinguido do terceiro:

Os valores da escrita agem somente como grandezas opostas em um sistema definido; eles são opositivos, só se tornam valores por oposição. Há um limite no número de valores (Não é exatamente a mesma coisa que 2), mas se resolve finalmente no valor negativo) ${ }^{35}$.

\footnotetext{
32 Enfase de Maniglier.

${ }^{33}$ Ênfase de Maniglier.

${ }^{34}$ ELG, p. 80.
} 
O que ele retoma imediatamente a propósito da linguagem:

2) O valor negativo da palavra é evidente. Tudo consiste em diferenças. 3) O valor se torna positivo graças à oposição, pela vizinhança, pelo contraste [...]. Esses signos agem, portanto, não por seu valor intrínseco, mas por sua posição relativa, como em um jogo de xadrez ${ }^{36}$.

Saussure não somente distingue conceitualmente diferença e oposição, mas também distingue conceitualmente a entidade determinada pela combinação de diversos traços diferenciais, que ele chama de termo, daquilo que constitui mais rigorosamente o valor, que não é outra coisa que o termo redeterminado pelos termos circundantes, ou seja, as oposições entre ele e os outros termos dados (sobre a base de suas diferenças):

O valor de uma palavra resultará unicamente da coexistência dos diferentes termos. O valor é a contrapartida dos termos coexistentes ${ }^{37}$.

É preciso notar que, nesse nível, pode-se não levar em conta que o signo é uma entidade obtida de duas substâncias ao mesmo tempo. Consideram-se os termos como dados e mostra-se que eles são necessariamente determinados pelo que há em torno deles, pelo que eles não são. Pode-se muito bem estudar a língua até certo ponto, abstraindo-se totalmente da natureza desses termos do ponto de vista das substâncias (fônicas ou psicológicas) e do caráter preciso de suas diferenças, e concentrando-se somente nas relações entre os termos, ou seja, precisa Saussure, na identidade ou não identidade entre eles, ou em seu número:

\begin{abstract}
Uma apreciação sensata do que é o mecanismo de uma língua revela que há apenas uma importância muito limitada em conhecer os valores absolutos que nela se encontram, contanto que sua oposição - que não significa, aqui, sua diferença, mas apenas sua identidade ou não identidade, ou, em definitivo, seu número - se ache rigorosamente observada ${ }^{38}$.
\end{abstract}

Não é necessário saber quais diferenças precisas um signo conjuga, mas somente o que há em torno dele, aquilo pelo qual ele é substituível. Nesse sentido, chega-se a um sistema puramente formal, onde o que conta é unicamente a posição dos termos uns relativamente aos outros. Pode-se considerar até certo ponto a interioridade de um valor como uma caixa preta, o que se pode chamar, parodiando Quine, o princípio da inescrutabilidade relativa dos valores. É possível descrevê-la não mais unicamente enumerando todos os seus

\footnotetext{
${ }^{35}$ CLG, p. 139; SAUSSURE, Ferdinand de. Cours de linguistique générale, op. cit., p. 269, n. 1932.

${ }^{36}$ Ibid., p. 270, n. 1936.

${ }^{37}$ Ibid., p. 259, n. 1864. Ver também os seguintes textos: "O valor de uma palavra não será jamais determinado senão pelo concurso dos termos coexistentes que a limita; ou, para melhor se apoiar sobre o paradoxo em relevo: o que está na palavra não é jamais determinado senão pelo concurso do que está em torno dela (o que está na palavra é o valor) - em torno dela sintagmaticamente ou em torno dela associativamente. É preciso abordar a palavra de fora, partindo do sistema dos termos coexistentes". Ibid., p. 260, n. 1975, ênfase de Maniglier. "Esse valor resultará da oposição dos termos na língua”. Ibid., p. 263, n. 1894, ênfase de Maniglier.

${ }^{38}$ ELG, p. 210.
} 
traços distintivos, mas colocando-a em um campo de termos aparentados, que são eles próprios combinações de traços distintivos. É assim que Saussure procede no capítulo sobre o "mecanismo da língua", a propósito do termo "ensinamento". Cada termo se define em relação a todos os outros, mas em uma proporção desigual: é porque um termo não se opõe igualmente a todos os outros que ele pode ser determinado precisamente. Essa hierarquia permite que haja uma parte do termo que varia e outra que não varia, de acordo com uma relação de semelhança e dessemelhança, com dois termos se opondo mais quanto mais arriscam ser confundidos. A diferença entre a oposição e a diferença é conceitual: trata-se de dois registros da variação. Além de supor que os termos já estejam dados, a oposição supõe sempre uma variação na unidade, ou seja, um termo que varia e um termo que não varia. Mas a diferença não é medida em relação a uma constante; ela é determinada, como mostramos, somente pela correlação com outra diferença.

Essas duas relações estão, contudo, intimamente misturadas uma à outra. Há como que uma integração da oposição na diferença. $\mathrm{O}$ traço distintivo determina a entidade linguística não somente ao qualificar ou condicionar a costura [capitonnage] dos dois planos qualitativos, mas também agora ao permitir distinguir essa combinação complexa de traços distintivos heterogêneos de outra combinação oposta no sistema. Nesse sentido, a diferença funciona como critério da oposição. Reciprocamente, a distinção ou oposição entre os termos depende do controle dos traços diferenciais. Um hispanófono terá dificuldade em distinguir entre "le vent" e "le banc". Sabese bem que a língua japonesa não faz diferença entre o "r" e o "l"; Pinker o ilustra com uma brincadeira de gosto duvidoso feita pelo linguista Masaaki Yamanashi, que o acolheu um dia dizendo-lhe: "Aqui no Japão temos

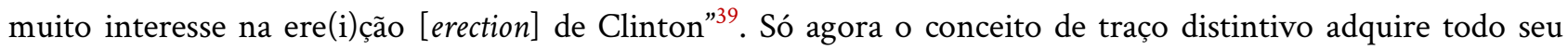
sentido. É possível dizer então que o traço de labialização distingue a entidade "total" [sommeil] (sono) da entidade total [soleil] (sol).É assim que se explica o fenômeno para o qual Saussure chamava atenção, que estará no núcleo da noção de fonema e que ele chamava de "flutuação": a realização de um valor pode ser alterada em proporções bem substanciais, desde que ela não recubra um valor existente ${ }^{40}$. Assim, /sommeil/ (sono) pode perder seu traço de labialização e se pronunciar /sonneil/ou /sommile/ desde que permaneça distinto de /soleil/ (sol) ou de /sommier/ (estrado da cama). Se uma palavra desaparece de uma língua, seu domínio de realização (fônica e semântica) fica livre para os termos circundantes que assim mudam de valor, ainda que eles não tenham mudado de natureza. Assim, [jugement] (julgamento) permanece [jugement] (do ponto de vista de seus traços diferenciais), mas seu valor muda, o que pode fazer, a curto ou longo prazo, com que os traços diferenciais inúteis se transformem.

Assim, a opositividade define o domínio da linguística "pura", da língua "nela mesma e para ela mesma". É porque há redeterminação das diferenças pelas oposições e, logo, "determinação recíproca" dos valores uns pelos outros que a linguística pode considerar esses termos como termos algébricos, ou seja, definidos unicamente uns pelos outros em função de suas relações recíprocas. É o fundamento da linguística sincrônica. Mas vê-se que essa autonomia da língua é secundária, e que ela é frágil. Pode se tornar necessário conhecer os "valores absolutos", especialmente quando um fonema se altera por razões materiais ou substanciais, e não formais. Em outras palavras, pode ser necessário se interessar pela natureza dos traços diferenciais que servem

\footnotetext{
${ }^{39}$ PINKER, Steven. O instinto da linguagem. São Paulo: Martins Fontes, 2002, p. 214.

${ }^{40}$ Assim, o "r" em francês pode ser ápico-alveolar, ao contrário do alemão, o "t", molhado, ao contrário do russo etc. CLG, p. 138 .
} 
para marcar as oposições. Seria possível mostrar que, do ponto de vista propriamente teórico, o objetivo dessa teoria do valor é mostrar que de tanto falar uma lingua termina-se por falar outra, ou para dizê-lo de outro modo, que só se pode comparar os sistemas simbólicos com jogos à condição de perceber que as regras do jogo não param de mudar à medida mesma que se joga. Contentemo-nos somente de notar que ela vale como uma resposta para o problema filosófico da gênese do inteligível a partir do sensível, que se distingue das duas grandes opções nas quais a modernidade filosófica se repartiu: o projeto de uma gênese empírica e o de uma reconstrução transcendental. Ela afirma, com efeito, que é a pluralidade de níveis da sensibilidade que per mite introduzir unidades que nem se encontram dadas na experiência, nem são introduzidas pela função sintética do espírito. É a essas idealidades estranhas que, sob o nome de signos, somos entregues. Gilles Deleuze ${ }^{41}$ tinha então razão para fazer do critério "simbólico" - como terceiro face ao real e ao conceito, nem físico nem moral, incorporal mas real - o primeiro critério que permite reconhecer o estruturalismo. Pode-se apostar que se trata ainda de um critério para o futuro.

\section{Referências}

BERGSON, Henri. Les données immédiates de la conscience. Paris: PUF, 1889.

BERGSON, Henri. Ensaio sobre os dados imediatos da consciência. Trad. João da Silva Gama. Lisboa: Edições 70, 1989.

Chomsky, Noam; Halle, Morris. Principes de phonologie générative. Trad. Pierre Encrevé. Paris: Minuit, 1973.

DELEUZE, Gilles. Différence et Répétition. Paris: PUF, 1968.

DELEUZE, Gilles. Logique du sens. Paris: Minuit, 1969.

DeleuZe, Gilles. À quoi reconnaît-on le structuralisme. In: CHATELET, François. Histoire de la philosophie, t. VIII : le XX' siècle. Paris: Hachette, 1972, p. 299-335.

DeleuZE, Gilles. Lógica do sentido. Trad. Luiz Roberto Salinas Fortes. São Paulo: Perspectiva, 1974.

DeleuZE, Gilles. Em que se reconhece o estruturalismo. In: CHÂTELET, François. História da filosofia, t. VIII: o século XX. Rio de Janeiro: Zahar, 1982, p. 271-303.

DELEUZE, Gilles. L'île déserte et autres textes. Textes et entretiens, 1953-1974. Paris: Minuit, 2002.

DeleuZE, Gilles. Diferença e Repetição. Trad. Luiz Orlandi e Roberto Machado. São Paulo: Graal, 2009.

DELEUZE, Gilles. A ilha deserta e outros textos: textos e entrevistas (1953-1974). Trad. Luiz Orlandi. São Paulo: Iluminuras, 2008.

DERRIDA, Jacques. De la grammatologie. Paris: Minuit, 1967.

DERRIDA, Jacques. Marges de la philosophie. Paris: Minuit, 1972.

DERRIDA, Jacques. Margens da filosofia. Trad. Joaquim Torres Costa e Antônio M. Magalhães. Campinas: Papirus, 1991.

\footnotetext{
${ }^{41}$ DeLEUZE, Gilles. Em que se reconhece o estruturalismo in: História da filosofia, t. VIII: o século XX. Rio de Janeiro: Zahar, 1982, p. 271-303.
} 
DERRIDA, Jacques. Gramatologia. Trad. Miriam Schnaiderman e Renato Janine Ribeiro. São Paulo: Perspectiva, 2016.

DESCOMBES, Vincent (1979). Le même et l'autre, Quarante-cinq ans de philosophie française (1933-1978). Paris: Minuit, 1979.

Hegel, G. W. F. Science de la logique, Premier Tome, Deuxième Livre, La doctrine de l'essence. Trad. Labarrière, Pierre-Jean et Jarczyck, Gwendoline. Paris: Aubier-Montaigne, 1976

Hegel, G. W. F. Ciência da Lógica: 2. A Doutrina da Essência. Trad. Christian G. Iber e Federico Orsini. Petrópolis: Vozes, 2017.

JAKOBSON, Roman. Essais de linguistique générale. Paris: Minuit, 1963.

JAKOBSOn, Roman; WAUGH, Linda. La charpente phonique du langage. Trad. Alain Kim. Paris: Minuit, 1979.

LACAN, Jacques. Le Séminaire Livre III, Les psychoses, 1955-1956. Paris: Seuil, 1981.

LACAN, Jacques. O Seminário Livro 3, as psicoses, 1955-1956. Versão de Aluísio Menezes. Rio de Janeiro: Jorge Zahar, 1985.

MANIGLIER, Patrice. Le vocabulaire de Lévi-Strauss. Paris: Ellipses, 2002.

MANIGLIER, Patrice. La langue, cosa mentale. In: Saussure. Paris: Editions de l' Herne, 2003.

MiLNER, Jean-Claude. L'amour de la langue. Paris: Seuil, 1978.

Milner, Jean-Claude. O amor da Língua. Trad. Paulo Sérgio de Souza Jr. Campinas: Editora Unicamp, 2012.

PAVEL, Thomas. Le mirage linguistique, essai sur la modernité intellectuelle. Paris: Minuit, 1988

PAVEL, Thomas. A miragem linguística, ensaio sobre a modernidade intelectual. Trad. Eni Orlandi, Pedro de Souza e Selene S. Guimarães. Campinas: Pontes, 1990.

PINKER, Steven. L’instinct du langage. Trad. Marie-France Desjeux. Paris: Odile Jacob, 1999

PINKER, Steven. O instinto da linguagem. Trad. Claudia Berliner. São Paulo: Martins Fontes, 2002.

RASTIER, François. Sémantique interprétative. Paris: PUF, 1987.

RASTIER, François. Sémantique et recherches cognitives. Paris: PUF, 1991.

SAUSSURE, Ferdinand de. Cours de linguistique générale, édição crítica de Rudolf Engler, Wiesbaden: Otto Harrassowitz, Tome 1, 1967.

SAUSSURE, Ferdinand de. Cours de Linguistique générale. Paris: Payot, 1972.

Saussure, Ferdinand de. Curso de Linguística Geral. Trad. Antônio Chelini, José Paulo Paes e Izidoro Blikstein. São Paulo: Cultrix, 2006.

SAUSSURE, Ferdinand de. Écrits de linguistique générale. Paris: Gallimard, 2002.

SAUSSURE, Ferdinand de. Escritos de linguística geral. Trad. Carlos Augusto Leuba Salum e Ana Lúcia Franco. São Paulo: Cultrix, 2004.

Troubetzkoy, N. S. Principes de phonologie. Trad. J. Cantineau. Paris: Librairie C. Klincksieck, 1949.

Recebido em: 11 de fevereiro de 2020 